\title{
High prevalence and low cure rate of tuberculosis among patients with HIV in Xinjiang, China
}

\author{
Rena Maimaiti ${ }^{1}$, Yuexin Zhang ${ }^{2}$, Kejun Pan², Peierdun Mijiti ${ }^{3}$, Maimaitiali Wubili², Maimaitijiang Musa ${ }^{4}$
} and Rune Andersson ${ }^{5^{*}}$

\begin{abstract}
Background: Tuberculosis and HIV co-epidemics are problems in many parts of the world. Xinjiang is a high tuberculosis and HIV prevalence area in China. We aimed to investigate the prevalence and cure rate of tuberculosis among HIV positive patients in Xinjiang.

Methods: In a retrospective study between 2006 and 2011, clinical and laboratory data on 333 patients with HIV and tuberculosis were compared to 2668 patients with HIV only. There were 31 HIV positive patients with no data on tuberculosis.

Results: The prevalence of tuberculosis co-infection among the HIV positive patients was $11 \%(95 \% \mathrm{Cl} 10-12 \%)$, significantly higher than the national figure in China of 2\%. In most cases HIV was diagnosed late, with advanced immunodeficiency. The use of isoniazid preventive therapy was only $57.9 \%$ in patients without tuberculosis who fulfilled the criteria for receiving this prevention. The cure rate one year after diagnosis was $69.2 \%$, which was lower than the officially reported $91.4 \%$ in all tuberculosis cases in Xinjiang in 2011. The hazard of not surviving over the five years was significantly higher in patients with HIV + tuberculosis compared to HIV only after adjusting for sex and Intravenous drug use with $\mathrm{HR}=1.84$ (95\% Cl 1.43-2.35; $p<0.0001)$.

Conclusions: The prevalence of tuberculosis among HIV positive patients in Xinjiang was higher than in China taken as a whole, and HIV was diagnosed late, with underuse of isoniazid preventive therapy. The low cure rate and reduced survival can be due to late diagnosis of HIV and no testing for antibiotic resistance, together with insufficient control of adherence to the treatment regimens for tuberculosis and HIV.
\end{abstract}

Keywords: HIV, Tuberculosis, Isoniazid prophylaxis, Treatment outcome

\section{Background}

Mycobacterium tuberculosis (TB) and human immune deficiency virus (HIV) infections are major public health problems in many parts of the world, particularly in low and middle-income countries [1, 2]. In 2013, an estimated 9.0 million people developed TB and 1.5 million died from the disease. Of these, about 1.2 million (14\%) had a HIV co-infection [3]. China has the world's second largest number of tuberculosis cases after India (12 and $26 \%$ of global cases, respectively) in 2012 [4]. WHO

\footnotetext{
* Correspondence: rune.andersson@gu.se

${ }^{5}$ Department of Infectious Diseases, Institute of Biomedicine, Sahlgrenska

Academy at Gothenburg University, Göteborg, Sweden

Full list of author information is available at the end of the article
}

estimated the prevalence of TB (including HIV + TB) in China 2012 to be $1,400,000(1,200,000-1,600,000)$. The incidence rate of new TB infections was $99(86-113) /$ 100,000 [4].

Several studies have indicated that TB co-infection increases the risk of HIV progression and death, particularly in persons with untreated HIV [5].

HIV infection is associated with immunosuppression, which in turn increases the risk of latent $\mathrm{TB}$ infection developing into active TB [6, 7].

After contact with tuberculosis bacteria, patients with HIV have 20 times the normal incidence of TB [8]. This risk can be reduced by isoniazid preventive therapy (IPT), with benefits for both the individual and for the 
further spread of $\mathrm{TB}$, and it is generally accepted that the lifetime risk of TB reactivation in the HIV positive group can be reduced from about 30 to $4 \%[9,10]$.

HIV positive patients with $\mathrm{TB}$ and low $\mathrm{CD}^{+}$ T-lymphocyte counts $\left(<100\right.$ cells $\left./ \mathrm{mm}^{3}\right)$, more often present with atypical chest $\mathrm{X}$-rays and negative acid-fast bacilla (AFB) sputum smears, compared to HIV-negative patients [11].

Xinjiang Uygur Autonomous Region is a province in the Northwestern part of China, with 21,815,815 inhabitants in 2011. The incidence of TB in Xinjiang was 2003-2008 estimated at 463 cases per 100,000 persons per year [12]. The information on the prevalence of multidrug-resistant (MDR) and extensively drugresistant (XDR TB) remains scant in the region, due to TB drug susceptibility testing (DST) not being implemented as a routine test at most hospitals. It was performed in combination with a clinical study in Urumqi from 2009 to 2011, and indicated a prevalence of MDR TB of $13.2 \%$ [13].

One study from January 2007 to June 2010, including 11 counties in Xinjiang, reported that the HIV screening rate was $79.1 \%$ in the TB patients' group, and the rate of positive HIV was $2.2 \%$ among those tested. TB was tested for in $85.3 \%$ of the HIV positive patients, of whom $10.8 \%$ were diagnosed with TB [14].

At screening for HIV among patients with tuberculosis in the 15 counties in Xinjiang 2007, the prevalence was $1.2 \%$ [15]. At the TB hospital, Urumqi, all patients with TB were tested for HIV between 2009 and 2012. 6.2\% of the TB patients were co-infected with HIV, with stable prevalence rates over time.

The availability of HIV testing in Xinjiang was not the same the whole time period and many times offered in projects directed towards high risk groups. In Xinjiang the HIV infection prevalence in the drug users was $21.4 \%$ from one study 2010 [16].

\section{Objectives}

The objectives of the study were to investigate the prevention, prevalence, and cure rate of tuberculosis among HIV-positive patients in Xinjiang, China.

\section{Methods}

A cross-sectional retrospective study was carried out between November 2006 and December 2011, and identified 3032 HIV-positive patients at the HIV clinics of three city hospitals in Xinjiang, China. The patients were treated in Urumqi (729), Yili (1861) and Kuqa (442). The total populations in the three cities were respectively 3.11 million (2011), 515,000 (2011) and 475,000 (2010).

Doctors and nurses specializing in infectious diseases at these hospitals were responsible for the collection of data. Register forms were used to collect data on demographic factors and clinical features.

The 2001 revised diagnostic criteria for the diagnosis and treatment of pulmonary tuberculosis were used [17]: 1. Positive culture of Mycobacterium tuberculosis from sputum, tissue, blood, liver, spleen, lymph nodes, biopsy or pleural effusion. 2. Persistent high fever $\left(>38.5{ }^{\circ} \mathrm{C}\right)$ more than two weeks, or night sweats, or more than $10 \%$ weight loss (3-6 months),or weakness. 3. Positive tuberculin test (PPD), where the scleroma was moderate $(10-19 \mathrm{~mm})$ or intense $(>20 \mathrm{~mm})$, or with blister, local necrosis, lymphangitis). 4. Chest X-ray image showing changes typical of tuberculosis. Patients fulfilling the first criterion, or two of the others, were diagnosed with TB.

All the patients, irrespective of whether they had signs and symptoms of chest infection, were screened for pulmonary TB by chest X-ray, and then by examination of sputum for AFB using standard techniques. Blood samples were collected periodically every 6 months and tests included a CD4 cell count. Routine blood tests included red blood cells, white blood cells, platelet count and hemoglobin. HIV viral loads were not routinely analyzed.

Patients with CD4+ T lymphocyte count $<350 / \mu \mathrm{l}$, or CD4+ T lymphocyte count $>350 / \mu$ l together with one of the following symptoms were eligible for antiretroviral treatment: enlarged lymph nodes,persistent fever for several months, night sweats, more than $10 \%$ weight loss, diarrhea, generalized herpes infection, oral Candida albicans infection.

The first line antiretroviral treatment (ART), given was two nucleoside reverse transcriptase inhibitors (NRTIs) plus a non-nucleoside reverse transcriptase inhibitor (NNRTIs) as combination therapy. The available first line drug combinations were: zidovudine $(\mathrm{AZT})+$ lamivudine $(3 \mathrm{TC})+$ nevirapine (NVP), AZT + 3TC+ efavirenz $(\mathrm{EFV})$ or stavudine $(\mathrm{D} 4 \mathrm{~T})+3 \mathrm{TC}+\mathrm{NVP}$. The second line treatments were tenofovir (TDF) $+3 \mathrm{TC}+$ lopinavir (LPV) or TDF + 3TC + EFV. The drugs were supplied by the state free of charge.

In China, the National TB Control Program (NTP) is implemented directly through a network of $\mathrm{TB}$ centers and TB hospitals, and is also used at HIV clinics [18]. Tuberculosis drug treatment is generally given according to a standard scheme: $H$ (isoniazid), $\mathrm{R}$ (rifampicin), $\mathrm{Z}$ (pyrazinamid), E (ethambutol) for 3 months, then reduced to isoniazid and rifampicin for an additional 3 months. Some patients (like patients with TB meningitis, or chest X-ray without improvement) were given extended treatment for 9 months or one year. The HIV positive patients treated at the HIV clinics were followed-up in the actual study. For the HIV negative patients treated at the TB centers and TB hospitals, we have no data on adherence to treatment or follow-up 
programs, and only reports of case fatalities. We have no information about whether the patients in our study had been treated at $\mathrm{TB}$ centers previously.

HIV positive patients with $\mathrm{CD} 4<100 / \mu \mathrm{l}$ were recommended IPT. In addition, patients with $\mathrm{CD} 4<250 / \mu \mathrm{l}$ together with weight loss, lymph node enlargement or PPD where the scleroma was $5-10 \mathrm{~mm}$, were recommended IPT.

In this study, no patient underwent the TB resistance test, because it was not available at the general hospitals in Xinjiang. The study from between 2009 and 2011 on the prevalence of MDR-TB [13] did not include the patients in this study.

During the treatment, the patients were monitored for CD4 cell count, levels of liver enzymes, chest X-ray in cases with lung symptoms like cough or sputum.

\section{Statistical methods}

For comparison of proportions between groups we used Chi-square test. The differences in hazard between groups were analyzed by Cox proportional hazard analysis. Survival curves based on Kaplan-Meier estimates are presented. $P$-values $<0.05$ were regarded statistically significant.

We analyzed the cure rate one year from the diagnosis of TB. We defined a TB cure as patients surviving the treatment period, having a negative sputum smear if previously the smear was positive, no remaining TB- related symptoms, and an improvement in chest or extrapulmonary X-ray findings, and no relapse after the end of TB treatment, relapse was defined as having a positive culture 30 days after the last treatment date [19]. Patients who stopped treatment before full term and patients lost to follow-up were regarded as treatment failures. Patients who transferred to other clinics, and surviving patients followed for less than one year, were excluded from the analysis of cure rate.

\section{Results}

The flow chart describing the included patients in the study is shown in Fig. 1.

\section{Sociodemography}

The demographic data on the patients with HIV + TB and HIV only are shown in Table 1.

The prevalence of TB among the HIV positive patients was $333 / 3032(11 \%)$, it was higher in men than in women $(14 \%$ vs $7 \%, p<0.05)$.

For the patients with extra-pulmonary TB (EPTB) the mean age was 39.2 years (median 38, range 27-52).

The main route of the HIV infection among patients with HIV + TB was Intravenous Drug Use (IVDU) at 58.3\% (95\% CI 53-63.6), which was significantly higher than for patients with HIV only, at 38.9\% (95\% CI 37.140.7); $p<0.05$.

Of the patients with HIV + TB, 72.7\% (95\% CI 6877.4) were men, which was significantly higher than for patients with HIV only where the figure was 55.3\% (95\% CI 53.4-57.2).

Hepatitis B surface antigen (HBsAg) was positive in 21 (6\%) of all 333patients with HIV + TB, with 14/21 (67\%) being HBV-DNA positive. Hepatitis $\mathrm{C}$ antibodies were

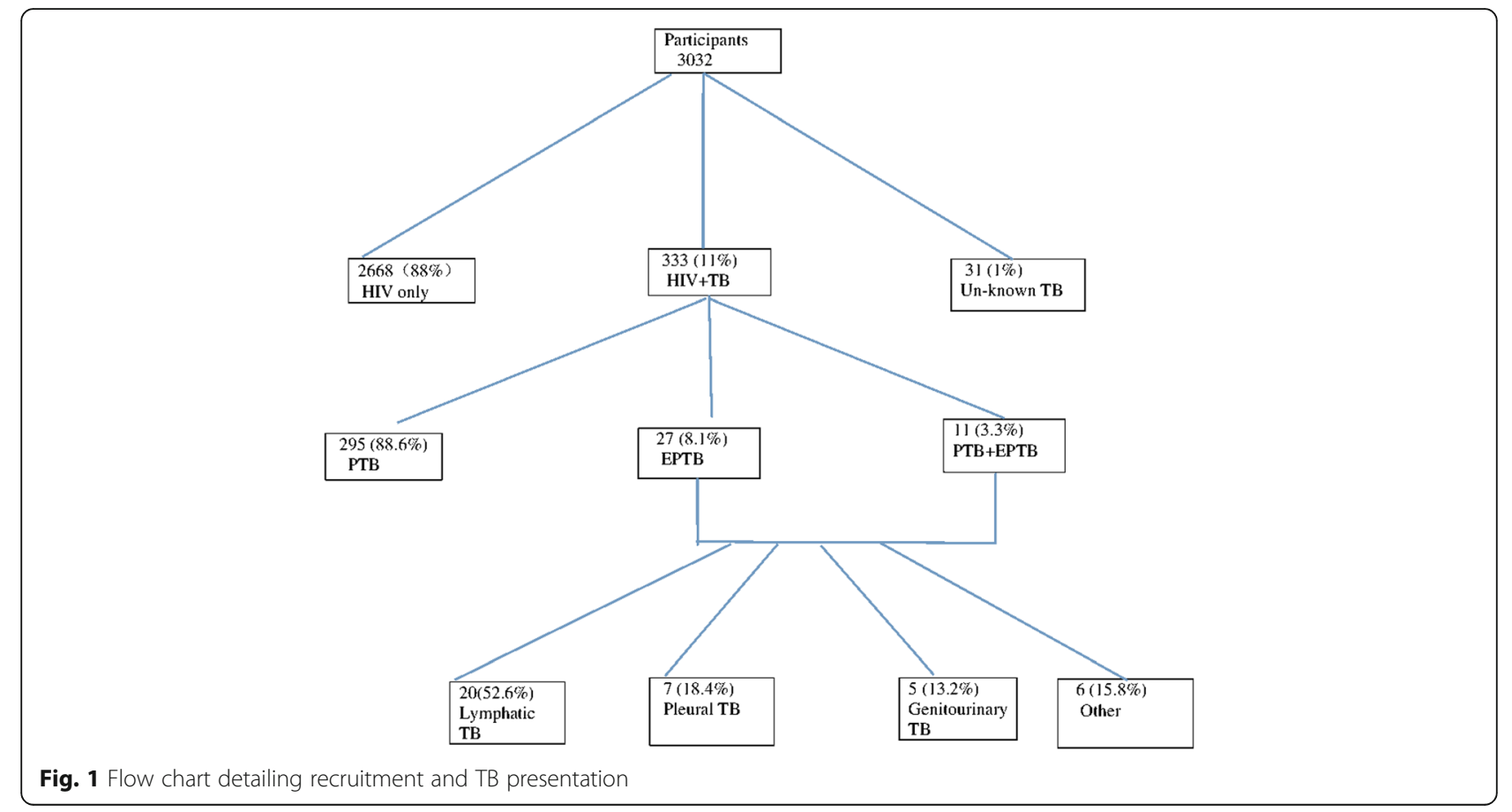


Table 1 Sociodemographic and clinical data

\begin{tabular}{|c|c|c|c|}
\hline & & $\begin{array}{l}\mathrm{HIV}+\mathrm{TB} \\
N=333\end{array}$ & $\begin{array}{l}\text { HIV only } \\
N=2668\end{array}$ \\
\hline \multirow[t]{2}{*}{ Sex } & Men & 242 & 1492 \\
\hline & Women & 91 & 1176 \\
\hline \multirow[t]{4}{*}{ Age } & $<29$ & 3 & 85 \\
\hline & $30-39$ & 105 & 917 \\
\hline & $40-49$ & 184 & 1316 \\
\hline & $>50$ & 41 & 381 \\
\hline \multirow[t]{4}{*}{ Ethnic } & Uygur & 287 & 2273 \\
\hline & Han & 30 & 308 \\
\hline & Hui & 10 & 109 \\
\hline & Other & 6 & 9 \\
\hline \multirow[t]{7}{*}{ Routes of infection } & Blood & 3 & 26 \\
\hline & IVDU & 194 & 1053 \\
\hline & Homosex & 1 & 38 \\
\hline & Sex & 94 & 1190 \\
\hline & MTCT & 0 & 1 \\
\hline & Unknown & 23 & 231 \\
\hline & No data & 18 & 160 \\
\hline \multirow[t]{4}{*}{ CD4 } & $<100$ & 122 & 492 \\
\hline & $100-249$ & 138 & 1083 \\
\hline & $>250$ & 71 & 1118 \\
\hline & No data & 2 & 6 \\
\hline \multirow{6}{*}{$\begin{array}{l}\text { Opportunistic } \\
\text { infections }\end{array}$} & Oral candida infection & 33 & 49 \\
\hline & PCP & 11 & 6 \\
\hline & Oral hairy leukoplakia & 2 & 16 \\
\hline & KS & 4 & 14 \\
\hline & Generalized herpes infection & 12 & 48 \\
\hline & Others & 9 & 27 \\
\hline
\end{tabular}

Abbrevations: IVDU (intravenous drug users), MTCT (mother-to- child transmission), PCP (Pneumocystis Jiroveci pneumonia), KS (Kaposis Sarkoma)

found in 83 (25\%) of the 333 patients, and 33/83 (40\%) were HCV-RNA positive.

Among the 1247 IVDUs 38\% were HBsAg positive and $40 \%$ were $\mathrm{HCV}$ - RNA positive. Data on treatment for hepatitis were not registered, but treatments were not free and it is likely most patients were untreated.

\section{Clinical symptoms}

The symptoms among patients with HIV + TB and HIV without TB are shown in Table 2. As shown, fever, cough, sputum production and night sweats were more common in the HIV + TB patients.

The average CD4 count at the time of HIV diagnosis was $169 / \mu \mathrm{l}$ in patients with $\mathrm{HIV}+\mathrm{TB}$, (median $146 / \mu \mathrm{l}$; range $2-931$ ), compared to $230 / \mu \mathrm{l}$ (median 223 , range $1-1668)$ in the patients without TB. Out of the patients with $\mathrm{HIV}+\mathrm{TB} 51.1 \%$ (95\% CI 45.8-56.4) had CD4 counts of less than 150, which was significantly more common than in patients with HIV only, at $35.2 \%$ (95\% CI 33.4-37).

Thirty-eight patients (11.4\%) had EPTB, of which 28 (74\%) were men. The largest proportion of EPTB cases had tubercular lymphadenitis $(53 \%)$, followed by pleural tuberculosis (18\%).

\section{Treatment of tuberculosis and HIV}

Of the 333 patients with TB, 292 (87.7\%) received treatment for TB. Six surviving patients had less than one year of follow-up, 7 (2.4\%) were lost to follow up, and 4 (1.4\%) were transferred to other clinics. Among the remaining 275 patients, 256 (93.1\%) started the TB treatment before the ART. But we have no any details regarding reasons for stopping treatment and for being lost during follow-up period.

\section{Isoniazid preventive therapy}

Among the 1161 patients without TB who fulfilled the criteria for IPT, it was given to $57.9 \%$ during the study period. Patients with intravenous drug use (IVDU) had lower rates of IPT 51.4\% (95\% CI 47.7-55.1) than nonIVDU patients, where 63.1\% (95\% CI 59.4-66.8) received the treatment. Men had a lower rate of IPT at $53.7 \%$ (95\% CI 50-57.4), than women, at 64.5\% (95\% CI 6168). Of the IVDU patients, $93.9 \%$ were men. No statistically significant difference was seen between ethnic groups, see Table 3.

\section{Cure rate and survival}

In our study the cure rate one year after diagnosis of TB could be evaluated for 234 patients and was 162/234 (69.2\%). Twenty-three other patients (9.8\%) had improved. No improvement in symptoms was seen among 18 patients $(7.7 \%)$ and $31(13.2 \%)$ had died. The causes of death were unfortunately not registered.

The survival time of HIV + TB patients was significantly shorter than in the patients with HIV only (Fig. 2). We note that reduced survival time among the patients with TB was marked during the first year, with no additional reduction of survival the following years (Fig. 2). The hazard of not surviving over the five years was significantly higher in patients with $\mathrm{HIV}+\mathrm{TB}$ compared to HIV only after adjusting for sex and IVDU with $\mathrm{HR}=1.84$ (95\% CI 1.43-2.35; $p<0.0001)$.

For the patients with IVDU there was no significantly different survival the first year. However, during the following years, this group had reduced survival rates year by year starting from the second year (Fig. 3).

Among the 333 patients with $\mathrm{HIV}+\mathrm{TB}$ data on other opportunistic infections were available for 275 patients. The surviving 203 patients had a median time of follow-up on 39 months. Out of them 21 
Table 2 Symptoms among patients with HIV + TB, and HIV only

\begin{tabular}{lllll}
\hline & HIV/PTB N=295 & HIV/EPTB N=38 & HIV + TB N=333 & $\begin{array}{l}\text { HIV only N=2668 } \\
n(\% ; 95 \% \mathrm{Cl})\end{array}$ \\
\hline Fever & $125(42.4 ; 36.7-48.1)$ & $12(32 ; 17.1-46.9)$ & $137(41.1 ; 35.8-46.6)^{*}$ & $392(14.7 ; 13.3-16.1)^{*}$ \\
Cough & $142(48.1 ; 42.4-53.8)$ & $7(18 ; 5.8-30.2)$ & $149(44.7 ; 39.4-50)^{*}$ & $472(17.7 ; 16.3-19.1)^{*}$ \\
Productive cough with sputum & $116(39.3 ; 33.8-44.8)$ & $5(13 ; 2.2-23.8)$ & $121(36.3 ; 31.2-41.4)^{*}$ & $389(14.6 ; 13.2-16)^{*}$ \\
Dyspnea & $28(9.5 ; 6.2-12.8)$ & $4(11 ; 1-21)$ & $32(9.6 ; 6.5-12.7)^{*}$ & $107(4.0 ; 3.3-4.7)^{*}$ \\
Sternalgia & $41(13.9 ; 10-17.8)$ & $3(8 ; 0-16.6)$ & $44(13.2 ; 9.7-16.7)^{*}$ & $104(3.9 ; 3.2-4.6)^{*}$ \\
Night sweats & $116(39.3 ; 33.8-44.8)$ & $11(29 ; 14.5-43.5)$ & $127(38.1 ; 32.8-43.4)^{*}$ & $344(12.9 ; 11.6-14.2)^{*}$ \\
Diarrhea & $22(7.5 ; 4.5-10.5)$ & $4(11 ; 1-21)$ & $27(8 ; 5-11)$ & $253(9.5 ; 8.4-10.6)$ \\
Nausea & $27(9.0 ; 5.7-12.3)$ & $2(6.0 ; 0-13.4)$ & $28(8.4 ; 5.4-11.4)$ & $240(9.0 ; 8-10)$ \\
Projectile vomiting & $3(1.0 ; 0-2.1)$ & $2(6.0 ; 0-13.4)$ & $3(1.0 ; 0-2.1)$ & $27(1.0 ; 0.6-1.4)$ \\
Headache & $38(12.9 ; 9.2-16.6)$ & $2(6.0 ; 0-13.4)$ & $40(12.0 ; 8.5-15.5)$ & $312(11.7 ; 10.5-12.9)$ \\
Blurry vision & $16(5.4 ; 2.9-7.9)$ & $1(3 ; 0-8.5)$ & $17(5.1 ; 2.7-7.5)$ & $179(6.7 ; 5.8-7.6)$ \\
Rash & $12(4.1 ; 2.1-6.1)$ & $2(6.0 ; 0-13.4)$ & $14(4.2 ; 2.2-6.2)$ & $115(4.3 ; 3.5-5.1)$ \\
Lymphadenectasis & $34(11.5 ; 7.8-15.2)$ & $11(29 ; 14.5-43.5)$ & $45(13.5 ; 9.8-17.2)^{*}$ & $160(6.0 ; 5-7)^{*}$ \\
\hline *P 0.05 & & & &
\end{tabular}

(10.3\%; 95\% CI $6.2-14.4 \%)$ had one or more previous or actual opportunistic infections (10 oral candida infection,6 generalized herpes infection, 2 Pneumocystis jiroveci pneumonia (PCP), 2 oral hairy leukoplakia, 1 Kaposi sarcoma.). Among 72 patients who had died, 16 had oral candida, 3 generalized herpes infection, 5 PCP, 2 Kaposi sarcoma. The rate of opportunistic infections in dead patients was 26/72 (36\% (95\% CI 24-47\%), statistically significantly higher than among the surviving patients.

Table 3 Isoniazid preventive therapy (IPT) for patients fulfilling the criteria for IPT

\begin{tabular}{lll}
\hline & $\begin{array}{l}\text { fulfilling the criteria } \\
\text { for IPT }(n=1161) N\end{array}$ & $\begin{array}{l}\text { IPT }(n=672) \\
N(\% ; 95 \% \text { Cl })\end{array}$ \\
\hline All & 1161 & 672 \\
Men $(n=1734)$ & 713 & $383(53.7 ; 50-57.4)$ \\
Women $(n=1298)$ & 448 & $289(64.5 ; 61-68)$ \\
Uygur $(n=2560)$ & 992 & $571(57.6 ; 53.9-61.3)$ \\
Han $(n=338)$ & 124 & $72(58.1 ; 54.4-61.8)$ \\
Other $(n=134)$ & 45 & $29(64 ; 60.5-67.5)$ \\
IVDU $(n=1247)$ & 519 & $267(51.4 ; 47.7-55.1)$ \\
Non-IVDU $(n=1785)$ & 642 & $405(63.1 ; 59.4-66.8)$ \\
Ongoing follow-up & 670 & $527(78.7 ; 75.7-81.7 \%)$ \\
$(n=2107)$ & & $42(33.6 ; 30.1-37.1)$ \\
Stop-ART $(n=367)$ & 125 & $70(25 ; 21.7-28.3)$ \\
Death $(n=426)$ & 280 & $27(35 ; 24-46)$ \\
Lost follow-up & 77 & $6(67)$ \\
( $n=106)$ & & \\
Transferred $(n=25)$ & 9 &
\end{tabular}

\section{Discussion}

The prevalence of TB co-infection in the HIV positive patients in Xinjiang was 11\% (95\% CI:10-12\%), which was significantly higher than the national figure in China of 2\% [4] in 2012 and also tended to be higher than in a study from Tanzania on 340 women coming to voluntary counselling and testing (VCT) center for HIV test with a figure of $5.3 \%(95 \%$ CI:0-10.6\%) [20]. In this study, we found that the higher prevalence of HIV + TB in men on $14 \%$ compared to $7 \%$ in women $(p<0.05)$. This could be due to the fact that $67.5 \%$ of the men and only $5.9 \%$ of the women were IVDU. TB/HIV co-infection was more prevalent in men also in a Tanzanian study [20], but in Tanzania there were not many IVDUs, but alcohol abuse was common among men.

Out of the patients in our study, $87.7 \%$ of patients coinfected with HIV and TB started treatment for both HIV and TB. This is a better figure than for China as a whole, where it is reported that only $23 \%$ of TB patients were tested for HIV in 2011 with 4715 (2\%) being HIV positive. Of these, only 1677 (36\%) received ART [21].

More than half of the patients with HIV + TB (51.1\%) had CD4 counts of less than 150, which was significantly more common than in patients with HIV only, at $35.2 \%$. It indicated a late diagnosis of HIV among the patients with TB.

Among the 1161 patients fulfilling the criteria for isoniazid prophylaxis, only $57.9 \%$ received the prophylaxis. Men had lower rate for prophylaxis treatment than women in our study. This could due to the fact that most of IVDUs were men, for whom preventive treatment is more difficult.

Extrapulmonar tuberculosis (EPTB) was seen among $11.4 \%$ (95\% CI:8.1-14.4) of patients in our study, which 


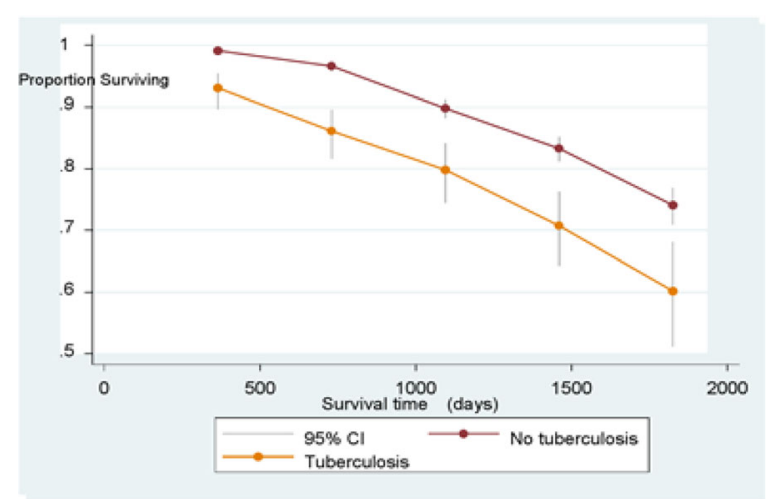

Fig. 2 Survival time in 333 patients with HIV + tuberculosis and in 2668 with HIV only

is similar to the global figure of $13 \%$ on all TB cases reported by WHO [22], but low compared to what is seen in study with 757 patients with HIV in Ethiopia with 25\% (95\% CI:19.7-30.3) [23]. We found that in our cases the most common types of ЕРTB were lymphadenitis (53\%) and pleural TB (18\%). Peto et al. published a wide series of EPT cases from the USA and revealed that lymphatic (40\%) and pleural (19.8\%) types of EPTB were the most frequent, and meningeal involvement was found in 5.4\% of their cases [24].

The cure rate of TB in our study was 162/234 (69.2\%) (95\% CI 66.2-72.2\%), lower than the officially reported 91.4\% for all cases of TB in Xinjiang 2011 [25], but similar as results of a study from Zimbabwe with 225 adult TB patients with a figure of $70 \%$ (95\% CI 50-90) [26]. The cure rate for EPTB was $34.2 \%$. There is no previously reported data from Xinjiang, but results are similar to those of a study from Taiwan of $28.7 \%$ [27]. Mortality among patients with EPTB was $36.8 \%$ in our study,compared to $14.7 \%$ in a study from the United States [28].

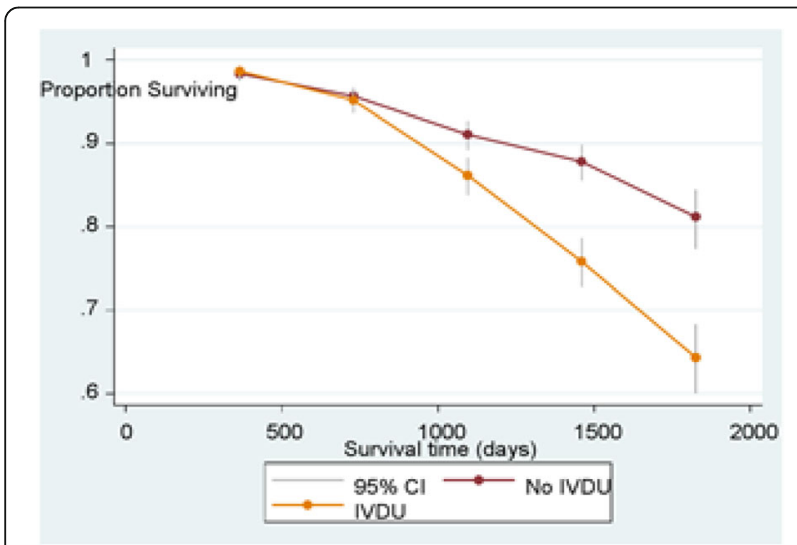

Fig. 3 Survival time in 1247 patients with intravenous drug use (IVDU) compared to 1353 patients with no IVDU. (For 432 patients data were missing)
Low TB cure rates among patients with HIV can be due to late HIV diagnosis with advanced immunodeficiency and no testing of TB resistance. Insufficient control of adherence to treatment regimens makes it impossible to evaluate if this can be a cause of the low cure rates. Both the treatment of TB and HIV need a high level of adherence to be successful.

According to WHO estimates, approximately 1 million new TB cases and 54,000 MDR-TB cases in 2013 [29] occur in China, Xinjiang is one of the areas in China with the highest prevalence [13]. The incidence of drug resistance is higher in the north, west, and central areas of China, and lower in south and east China [30-32].

However, testing for resistance was not performed in Xinjiang during the studied period, which blocked optimal treatment and control of TB.

Rapid and timely detection of TB cases and strengthened capacity to diagnose cases of drug-resistant TB are thus global priorities for TB care and control [7]. The Gene Xpert MTB/RIF test on sputum can in about $2 \mathrm{~h}$ detect $73 \%$ of culture positive acid fast bacilla (AFB) smear- negative TB cases from one specimen, and 90\% after three specimens in the study by Boehme et al. in study from Peru, Azerbaijan, South Africa, and India [33]. In a study in Ethiopia Gene Xpert had a sensitivity on culture- positive smear-negative TB cases of $57.4 \%$ with one sputum sample and $67.6 \%$ with two samples [34]. That and similar tests could allow for more rapid detection of tuberculosis and drug resistance outside reference centers, and cut delays in diagnosis, without the need to build large numbers of laboratories equipped to meet advanced biosafety [33] requirements. The problem is however the high cost.

Treatment discontinuation is considered as one of the risk factors for MDR-TB [35-38]. Although TB control and prevention in the Centre of Disease Control and prevention (CDC) system have professional follow-up systems, the patients from the hospitals are sometimes missed at transfer from hospitals to local TB dispensaries, and will thus not complete their follow-up treatment and get a high risk of drug resistance [30].

In this study the survival time of the IVDU patients was shorter than of non-IVDU patients. One important reason for low survival among HIV + IVDU patients can be the high proportion of patients with untreated hepatitis $B$ and C. Of the patients with IVDU $27 \%$ were $\mathrm{HBsAg}$ positive and $40 \%$ were HCV-RNA positive. There was no free treatment for hepatitis B or C in Xinjiang [39].

There are very limited economic resources in Xinjiang compared to developed cities like Beijing, Shanghai and Guangzhou. Although the Chinese government in recent years has implemented a new healthcare system, there is not enough money for patients in the whole country to receive good medical treatment from the onset of the disease. 
There is also limited skill in medical treatment in most of the rural hospitals. In addition, the patients' living conditions are often poor, with people crowding in the same living spaces to reduce costs of heating.

In the case of TB symptoms, many patients did not pay attention to them, because of lack of money. Although the TB drug are free for tuberculosis patients, they must afford the cost for auxiliary treatment, including drugs for reducing adverse reactions [40]. They have to pay for travel costs, tests and hospital care, which can discourage them, and may in turn lead to delayed diagnosis and treatment, with increased risk of spreading TB.

According to the results of a national general survey of tuberculosis between 2001 and 2010 in China, only $47 \%$ of patients with pulmonary tuberculosis went to the hospitals, and knowledge of TB prevention and control was only $57 \%$ [41].

A beneficial effect of immediate antiretroviral therapy was evident for reductions in rates of TB, Kaposi's sarcoma, and malignant lymphomas, meanwhile, the significant benefit in the immediate antiretroviral therapy in patients with HIV infection regardless of CD4+ count [42]. Hence, economic assistance should be available to ensure that TB patients with economic hardship can complete treatment, thus reducing the emergence of drug-resistant TB [40].

\section{Limitations}

This study was carried out in HIV clinics from 3 hospitals in Xinjiang. The data is dependent on the quality of the patient records, and we did not include CDC clinics, and private hospitals. For these reasons the results might not reflect the overall $\mathrm{TB}$ situation in this region. We lack data on the treatment outcomes of patients who were transferred. We have no data on whether patients were living in cities or rural areas. We also lack data on the causes of death.

\section{Conclusions}

The low cure rate of TB and reduced 5- year survival in the HIV positive patients could be caused by late diagnosis of HIV, no availability of TB resistance tests, together with a lack of documented high levels of adherence to HIV and TB treatment regimens.

Hence, economic assistance should be available to ensure that TB patients with economic hardship can complete treatment, thus reducing the emergence of drug-resistant TB.

\section{Abbreviations}

AFB: Acid-fast bacilla; ART: Antiretroviral treatment; AZT: Zidovudine; CDC: Centre of disease control and prevention; DST: Drug susceptibility testing; D4T: Stavudine; EFV: Efavirenz; ELISA: Enzyme-linked immunosorbent assay; EPTB: Extra-pulmonary tuberculosis; HIV: Human immune deficiency virus; IPT: Isoniazid preventive therapy; IVDU: Intravenous drug use; LAM: Lipoarbinomannan; LPV: Lopinavir; MDR: Multidrug-resistant;
NNRTIs: Non-nucleoside reverse transcriptase inhibitor; NRTIs: Nucleoside reverse transcriptase inhibitors; NTP: National TB Control Program; NVP: Nevirapine; PCP: Pneumocystis jiroveci pneumonia; PPD: Purified protein derivative skin test; TB: Tuberculosis; TDF: Tenofovir; XDR: Extensively drug-resistant; 3TC: Lamivudine; VCT: Voluntary counselling and testing

\section{Acknowledgements}

We thank Professor Max Petzold at Sahlgrenska Academy, Gothenburg University for help with the statistical analyses. Also thanks to Doctor Munira from VCT Center of the TB Hospital of Urumqi for help.

\section{Funding}

The study was supported by funds from The State Key Laboratory Base of Xinjiang Major Disease Research (2010DS 890294) and the Key Discipline Construction Fund of Xinjiang, Urumqi, China.

\section{Availability of data and materials}

The data is stored in a research database at the Xinjiang Medical University after removing the names and id-number of the patients. The patient records which the data is based on can't be shared due to the sensitive topic

\section{Authors' contributions}

RM undertook the acquisition of data, performed the analysis and interpretation of data, and drafted the manuscript. YZ, KP, MW and MM provided critical revision of the manuscript for important intellectual content. PM provided statistical support. RA developed the study concept and design, provided critical revision of the manuscript, and provided study supervision.

All authors read and approved the final manuscript.

\section{Competing interests}

The authors declare that they have no competing interests.

\section{Consent for publication}

Not applicable.

Ethics approval and consent to participate

The study was approved by the Ethics Committee of First affiliated Hospital of Xinjiang Medical University (approval 20090212-01).

\section{Author details}

'Department of Prevention and Health Care, The First Affiliated Hospital of Xinjiang Medical University, Urumqi, China. ${ }^{2}$ Department of Infection Diseases, The First Affiliated Hospital of Xinjiang Medical University, Urumqi, Xinjiang, China. ${ }^{3}$ Department of Epidemiology and Biostatistics, Xinjiang Medical University, Urumqi, China. ${ }^{4}$ The Clinic of Liudaowan Hospital of Urumqi, Urumqi, Xinjiang, China. ${ }^{5}$ Department of Infectious Diseases, Institute of Biomedicine, Sahlgrenska Academy at Gothenburg University, Göteborg, Sweden.

Received: 24 June 2016 Accepted: 22 December 2016 Published online: 05 January 2017

\section{References}

1. Harrington M. From HIV, to tuberculosis and back again: a tale of activism in 2 pandemics. Clin Infect Dis. 2010:50:S260-6.

2. Friedland G, Churchyard GJ, Nardell E. Tuberculosis and HIV coinfection: current state of knowledge and research priorities. J Infect Dis. 2007;196 Suppl 1:S1-3.

3. WHO TB Report 2014. http://apps.who.int/iris/bitstream/10665/137094/1/ 9789241564809_eng.pdf. Accessed 28 Dec 2016.

4. Global tuberculosis control. WHO report 2013, WHO/HTM/TB/2013.11. http://apps.who.int/iris/bitstream/10665/91355/1/9789241564656_eng.pdf. Accessed 10 Apr 2015

5. López-Gatell H, Cole SR, Hessol NA, French AL, Greenblatt RM, Landesman S, et al. Effect of tuberculosis on the survival of women infected with human immunodeficiency virus. Am J Epidemiol. 2007;165(10):1134-42.

6. Meya DB, McAdam KP. The TB pandemic: an old problem seeking new solutions. J Intern Med. 2007:261:309-29.

7. Girardi E, Raviglione MC, Antonucci G, Godfrey-Faussett P, Ippolito G. Impact of the HIV epidemic on the spread of other diseases: the case of tuberculosis. AIDS. 2000;14 Suppl 3:S47-56. 
8. WHO. Global tuberculosis control 2009: epidemiology, strategy, financinf Geneva: World Health Organization; 2009. http://apps.who.int/bookorders/ anglais/detart1.jsp? codlan=1\&codcol=15\&codcch=4659. Accessed $28 \mathrm{Dec}$ 2016.

9. Reddy KP, Brady MF, Gilman RH, et al. Microscopic observation drug susceptibility assay for tuberculosis screening before isoniazid preventive therapy in HIV-infected persons. Clin Infect Dis. 2010;50(7):988-96. doi:10.1086/651081.

10. Aït-Khaled N, Alarcon E, Bissell K, et al. Isoniazid preventive therapy for people living with HIV : public health challenges and implementation issues. Int J Tuberc Lung Dis. 2009;13(8):927-35.

11. Palmieri F, Girardi E, Pellicelli AM, et al. Pulmonary tuberculosis in HIVinfected patients presenting with normal chest radiograph and negative sputum smear. Infection. 2002;30:68-74.

12. Yuan $X$. The impact of the implementation of the DOTS strategy to TB control in Shihezi region. Endem Dis Bull. 2010;25(3):44-5.

13. Qi Y-C, Ma M-J, Li D-J, Chen M-J, Lu Q-B, Li X-J, et al. Multidrug-resistant and extensively drug-resistant tuberculosis in multi-ethnic Region, Xinjiang Uygur Autonomous Region, China. PLoS ONE. 2012;7(2):e32103. doi:10.1371/journal.pone.0032103.

14. Yuehua L, Wu G, Mahemuti M. Evaluation of Xinjiang fifth round of global fund tuberculosis and AIDS co-infection control project. China tuberculosis control collaboration. Lancet. 2010;32(11):767-9.

15. Yuehua $L$, Wang $X, X u e ~ F$, et al. Current status of HIV infection in patients with tuberculosis in Xinjiang. Dis Prev Control Bull. 2014;29(3):19-21.

16. Mingjian NI, Xueling CHEN, Jin CHEN, Wen HE, Wei LIU. HIV infection prevalence factors among drug users in Xinjiang. China J Public Health. 2013;29(8):1101-3.

17. Chinese society of tuberculosis, Chinese Medical Association. Tuberculosis diagnosis and treatment guidelines. Chinese J Tuberc Respir Dis. 2001;24(1):70-4

18. Piot A, Chaulet P. Implementing the WHO stop TB strategy: a handbook for national tuberculosis control programmes. Geneva: World Health Organization; 2008

19. Driver CR, Munsiff SS, Li J, Kundamal N, Osahan SS. Relapse in persons treated for drug-susceptible tuberculosis in a population with high coinfection with human immunodeficiency virus in New York City. Clin Infect Dis. 2001:33:1762-9.

20. Munseri PJ, Bakari M, Pallangyo K, Sandstrom E. Tuberculosis in HIV voluntary counselling and testing centres in Dar es Salaam, Tanzania. Scand J Infect Dis. 2010;42:767-74.

21. 2012 China AIDS Response Progress Report, Ministry of Health of the People's Republic of China 31 March 2012. http://www.unaids.org/sites/ default/files/country/documents//file,68497,ru...pdf. Accessed 28 Dec 2016.

22. World Health Organisation: Global tuberculosis control. WHO report; 2011. http://apps.who.int/iris/bitstream/10665/44728/1/9789241564380_eng.pdf. Accessed 28 Dec 2016.

23. Balcha T, Winqvist N, Sturegård E, Skogmar S, Reepalu A, Jemal ZH, et al. Detection of lipoarabinomannan in urine for identification of active tuberculosis among HIV-positive adults in Ethiopian health centres. Trop Med Int Health. 2014;19(6):734-42.

24. Peto HM, Pratt RH, Harrington TA, LoBue PA, Armstrong LR. Epidemiology of extrapulmonary tuberculosis in the United States, 1993-2006. Clin Infect Dis. 2009:49:1350-7.

25. Bureau of Health XUAR World TB Day. Bulletin.2011.3.23. http://www.xjwst. gov.cn. Accessed 10 Nov 2013.

26. Takarinda KC, Harries AD, Srinath S, Mutasa-Apollo T, Charles S, Mugurungi O. Treatment outcome of adult patients with recurrent tuberculosis in relation to HIV status in Zimbabwe: a retrospective record review. BMC Public Health. 2012;12:124.

27. Wang CS, Chen HC, Yang CJ, Wang WY, Chong IW, Hwang JJ, et al. The impact of age on the demographic, clinical, radiographic characteristics and treatment outcomes of pulmonary tuberculosis patients in Taiwan. Infection. 2008;36:335-40.

28. Leeds IL, Magee MJ, Kurbatova EV, del Rio C, Blumberg HM, Leonard MK, et al. Site of extrapulmonary tuberculosis is associated with HIV infection. CID. 2012:55(1):75-81

29. World Health Organization Global tuberculosis report 2014. World Health Organization, WHO/HTM/TB/2014.08. http://reliefweb.int/report/world/ global-tuberculosis-report-2014. Accessed 28 Dec 2016.
30. Yang Y, Li X, Zhou F, Jin Q, Gao L. Prevalence of drug-resistant tuberculosis in mainland China: systematic review and meta-analysis. PLoS One. 2011;6:e20343. doi:10.1371/journal.pone.0020343.

31. Yuding Z, Qin F, Ke T, Congcong Z, Honghu S, Tao L, et al. The population structure of drug-resistant mycobacterium tuberculosis clinical isolates from Sichuan in China. Infect Genet Evol. 2012;12:718-24.

32. Wright A, Zignol M, Van Deun A, Falzon D, Gerdes SR, Feldman K, et al. Epidemiology of anti-tuberculosis drug resistance 2002-07: an updated analysis of the global project on anti-tuberculosis drug resistance surveillance. Lancet. 2009:373:1861-73.

33. Boehme CC, Nabeta P, Hillemann D, Nicol MP, Shenai S, Krapp F, et al. Rapid molecular detection of tuberculosis and rifampin resistance. N Engl J Med. 2010;363:1005-15.

34. Taye T. Balcha, Erik Sturegård, Niclas Winqvist, Sten Skogmar, Anton Reepalu, Zelalem Habtamu Jemal, et al. Intensified Tuberculosis CaseFinding in HIV-Positive Adults Managed at Ethiopian Health Centers: Diagnostic Yield of Xpert MTB/RIF Compared with Smear Microscopy and Liquid Culture. PLoS ONE. 2014; 9(1): e85478. doi:10.1371. journal.pone. 0085478

35. Orenstein EW, Basu S, Shah NS, Andrews JR, Friedland GH, Moll AP, et al. Treatment outcomes among patients with multidrug-resistant tuberculosis: systematic review and meta-analysis. Lancet Infect Dis. 2009:9:153-61.

36. Faustini A, Hall AJ, Perucci CA. Tuberculosis treatment outcomes in Europe: a systematic review. Eur Respir J. 2005;26:503-10.

37. Franke MF, Appleton SC, Bayona J, Arteaga F, Palacios E, Llaro K, et al. Risk factors and mortality associated with default from multidrug-resistant tuberculosis treatment. Clin Infect Dis. 2008;46:1844-51.

38. Kritski AL, de Jesus LS R, Andrade MK, Werneck-Barroso E, Vieira MA, Haffner A, et al. Retreatment tuberculosis cases factors associated with drug resistance and adverse outcomes. Chest. 1997;111:1162-7.

39. Maimaiti R, Zhang Y, Pan K, Maimaiti W, Andersson R. Frequent coinfection with hepatitis among HIV-positive patients in Urumqi, China. J Int Assoc Phys AIDS Care (JIAPAC). 2013;12(1):58-61.

40. Yang $X$, Yuan $Y$, Pang $Y$, Wang B, Bai $Y$, Wang $Y$, et al. The Burden of MDR/ XDR Tuberculosis in Coastal Plains Population of China. PLoS ONE. 2015; 10(2): e0117361. doi:10.1371/journal. pone.0117361.

41. The Ministry of Health in China.2011. Bulletin. www.scio.gov.cn. Accessed 22 Mar 2013

42. Lundgren JD, Babiker AG, Gordin F, Emery S, Grund B, Sharma S, An-chalee A, et al. Initiation of antiretroviral therapy in early asymptomatic HIV infection. N Engl J Med. 2015;373:795-807. doi:10.1056/NEJMoa1506816.

\section{Submit your next manuscript to BioMed Central and we will help you at every step:}

- We accept pre-submission inquiries

- Our selector tool helps you to find the most relevant journal

- We provide round the clock customer support

- Convenient online submission

- Thorough peer review

- Inclusion in PubMed and all major indexing services

- Maximum visibility for your research

Submit your manuscript at www.biomedcentral.com/submit 